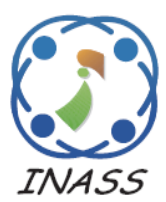

\title{
Designing an Efficient Mathematical Model for Different Thermal Insulation Material using Group Search Optimization
}

\author{
Anil Kumar Dixit ${ }^{1 *}$
}

\author{
Manmatha Kumar Roul ${ }^{2}$
}

Bikash Chandra Panda ${ }^{3}$

\author{
${ }^{1}$ Bhadrak Institute of Engineering \& Technology, Odisha, India \\ ${ }^{2}$ Gandhi Institute for Technological Advancement, Bhubaneswar, India \\ ${ }^{3}$ Indira Gandhi Institute of Technology, Sarang, Odisha, India \\ *Corresponding author’s Email: akdixit0465@gmail.com, anildixitcivil@gmail.com
}

\begin{abstract}
Of late, the concrete has established itself as the most extensively employed construction material in India. Based on the materials, various types of walls such as the Ferro cement wall, the Reinforced Cement Concrete (RCC) wall, and three other types of Cavity wall with different thickness and applied temperature are constructed. The proposed work carries out an extensive study on the mathematical modeling of designing the objective function $\left(f_{s}\right)$ found centered on the evaluation of the output parameter. Several optimization techniques are effectively employed to ascertain the optimal weight of the system. In the result the variations of the three algorithms were attained for the Ferro cement wall, the RCC wall, the combined Ferro cement and RCC walls, the combined twin ferrocement walls and the combined twin RCC walls. From the evaluation, the average is $96.8 \%$ in the overall process and the GSO algorithm shows the enhanced performance.
\end{abstract}

Keywords: Ferro cement wall, Reinforced Cement Concrete (RCC) wall, Mathematical modeling, Group Search Optimization (GSO).

\section{Introduction}

High Performance Concrete may be suitably explained as that distinctive brand of concrete, which meets with the unique competence and dependability constraints that cannot be always achieved routinely by using conventional materials and normal mixing, placing and curing procedures [1]. The concrete possess high compressive strength along with lots of valuable properties, such as high abrasion resistance, stiffness, low permeability, higher durability, higher early strength gain and lower cost per unit load [2]. Ordinary Portland Cement (OPC), in reality, is a significant material in the creation of concrete which usually functions as its binder to unite all the gathered materials [3]. The plan of the building envelope is important towards achieving an optimal configuration, which responds successfully to environmental changes in order to decrease their impact [4]. Renovating or supporting concrete beams by using repairing technique on the tension face of the beam (such as using reinforced concrete layer Ferro cement layer steel plates and FRP wrap laminates) regarded as one of the regular used repairing or strengthening techniques for beams [5]. The latest energy calamity and the environment impacts of building industry have led to the vigorous promotion of principles of sustainable improvement in current times [6]. Thermal performance of composite material however a very few references are accessible on thermal performance of complex with air gap [7]. The expression flat slab represents a reinforced concrete slab with or without drops, supported normally without beams, by columns with or without flared heads [8]. As the floor system performs an imperative role in the overall cost of a building, a post-tensioned floor system is discovered [9]. ACI 116 describes RCC as "concrete compacted by roller compaction; concrete that, in its unhardened condition, will hold up a roller while being compressed [10]. Steel-Mesh Reinforced Cementitious Composites (SMRCC) (traditionally 
known as ferrocement) emerges to be an option lowcost material for flat and corrugated roofing system and wall construction as it employs lesser quantities of natural resources as raw materials and appropriate for low-cost roofing and wall construction [11]. Minimum cover and minimum thickness condition of reinforced concrete structures effects in high self weight thus most of the load carrying capacity of reinforced concrete section goes to oppose the result of the self-weight of the member itself [12]. Wall is an imperative building component in building envelope, which needs apt design and construction, as it is most exposed to climatic elements [13]. Most heat $(>60 \%)$ is vanished or increased through the roof [14].The selection of a specific heat insulating system or material relies on many variables [15]. A specific ceiling material may be more competent in terms of thermal insulation than another [16] depending on how large or small the value of these thermal properties. Post-Tensioning is a technique of reinforcing concrete or other materials with highstrength steel strands or bars, naturally referred to as tendons [17]. At last, an appropriate insulating system along with suitable material combinations out of many will be advised based on employ of low cost local materials and skills for application in the RCC roof slab. The main objective of this research work predict the temperature parameters in different walls such as in RCC wall, Ferro cement wall and three sorts of cavity wall. This prediction analysis utilized to mathematical modeling with inspired weight optimization soft computing technique based on the different input constraints. The outcome of this proposed work gets maximum prediction accuracy and it's compared to other optimization techniques also. In section 2 there is an elaborate description regarding the literary reviews. Section 3 is rich with colorful data on the proposed technique. In section 4 discuss the prediction parameters and analyses for different techniques are compared. Section ends with a befitting conclusion. New features and main advantages of proposed work are predicting the temperature value for different walls with varying the thickness of the wall.

\section{Literature Review}

In 2015, M. V. Shoubi et al [18] have suggested that the materials, which are capable of cutting down the environmental impacts throughout the building's life span for instance, the amount of energy used), decides how far a building can withstand. The work was chiefly conducted to evaluate the diverse material combinations that can be employed with BIM for introducing a new substitute, which offers excellent solutions to decrement the energy usage at the time of operation.

In 2014, P. Biddulph et al [19] have stated how the thermal resistance as well as the effective thermal mass of a wall has been observed with the help of heat flux and temperature measurements. The effect of weather on the U-values was properly examined with the smaller time scale and the considerations related to thermal comfort was made available with the estimation of the effective thermal mass.

In 2013, Sangluaia et al [20] have studied about how the reinforced concrete lab would react, when it was applied with fire. In the thermal analysis phase, the temperature distribution in the profound region of the reinforced concrete lab under fire was found. Additionally, the assessment of the effects of the two materials in the RCC slab during peak temperature conditions was carried out.

In 2013, V. Rahman et al [21] have put forth the design of RCC along with its estimates, in addition to the Pre stressed Concrete flat slabs using a range of spans. It was apparent from the results that the shorter spans have lead to less expensive RCC, while the longer spans have caused the pre-stressed concrete flat slab to be more cheaper.

In 2012, Thirumal [22] have examined the way the Fiber Reinforced Ferro-cement Slabs react, when they are subjected to an impact. The percentage of fiber in the fibrous cement motor are varied as $1.5 \%, 2 \%$ and $2.5 \%$ of the entire volume of specimens to obtain the engineering properties such as, split tensile strength, flexural strength and compressive strength.

In 2012, G. Babu and A. Yerramala [23] have expressed the potential features, which are related to the largely feasible and high capacity fly ash Roller compacted concrete (RCC). Then, the concretes were examined to identify properties such as, split tensile strength, compressive strength and modulus of elasticity, rebound hammer number and ultrasonic pulse velocity.

\section{Proposed Method}

The temperature variation in the reverse face of the wall can be measured along with particular time duration depending on the walls like reinforced cement concrete (RCC) wall, Ferrocement wall and three sorts of cavity wall with varying thickness and the temperature applied over these walls. During real time testing, the associated time period may be very large. In the proposed mathematical modeling, the objective function $\left(f_{s}\right)$ is formulated in 
accordance with the measurement of the output parameter. About $70 \%$ of the input is used for training and the rest of the dataset allows the validation to be performed for the model produced. The use of optimization methodology in mathematical modeling helps in obtaining the optimal system weights $\alpha$ and $\beta$ to bring about a reduction in the modeling error. The optimal system weight can be achieved with a number of optimization algorithms such as bacterial colony optimization (BCO), the cuckoo search (CS) and group search optimization (GSO).

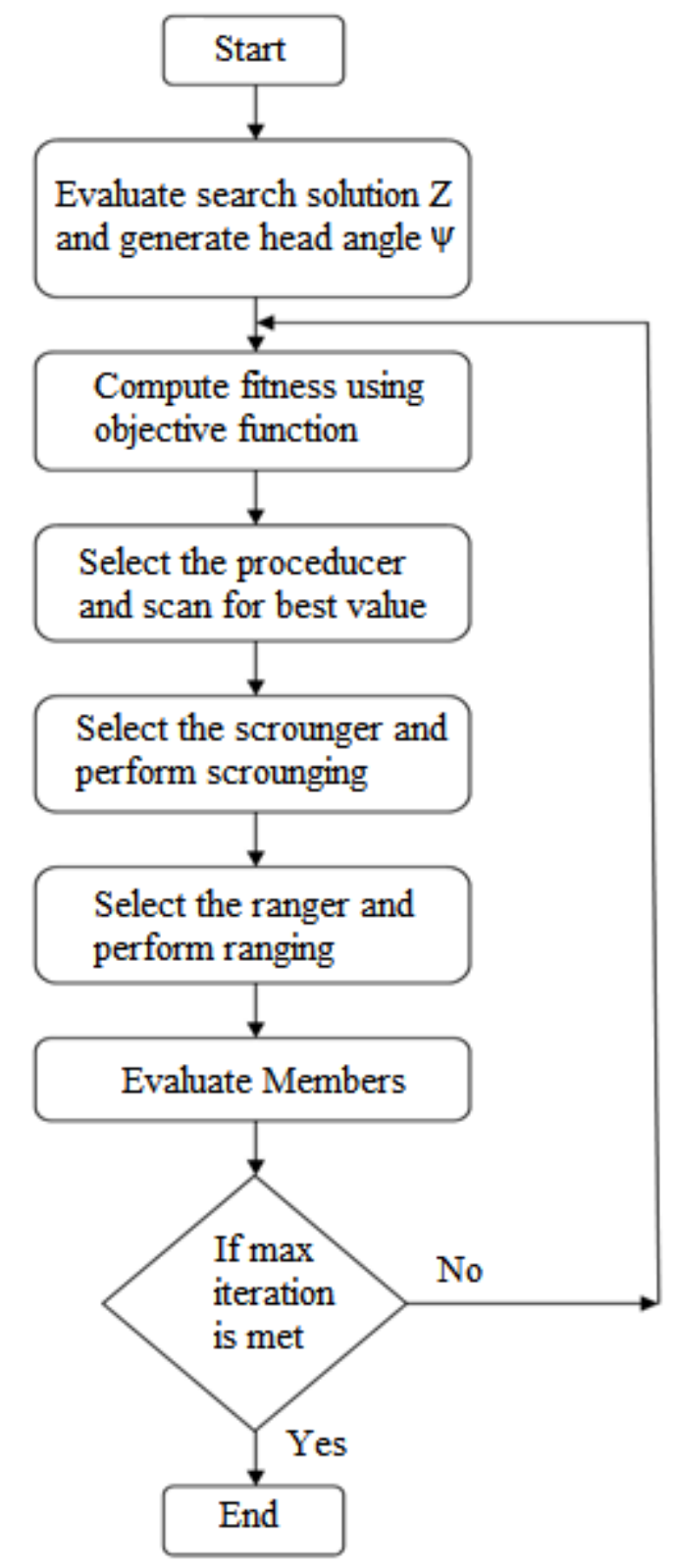

Figure.1 Flowchart for mathematical modeling with Group search optimization
If they gained results are not satisfactory, the training process is executed once more to make an adaptation in modeling in a suitable way for getting the desired output. The implementation of the entire process that is described above is performed using MATLAB.

In Figure.1, the flowchart associated with the Group Search Optimization (GSO) algorithm is being portrayed.

\subsection{GSO Algorithm}

The Group search optimization algorithm is developed with the motivation from the searching activity of animals. The searching activity of animals is mainly done with the intention of discovering resources that include food and shelter. The members within a group are of three kinds, namely, the producers, the scroungers and the rangers. The activity of the producers as well as the scroungers relies on the PS model. The rangers move in an arbitrary manner.

- Producers: These members go in search of resources.

- Scroungers: These members link the resources, which the producer discovers.

- Rangers: These are the members that make movements in an arbitrary manner and perform searching in an organized way, so that efficient finding of resources could be achieved.

$\Phi_{\max }$ represents the maximum search angle and $\mathrm{d}_{\max }$ denotes the maximum search distance.

Fig. 2 reveals the scanning field over which the producer does the scanning. The producer's position is indicated with the apex.

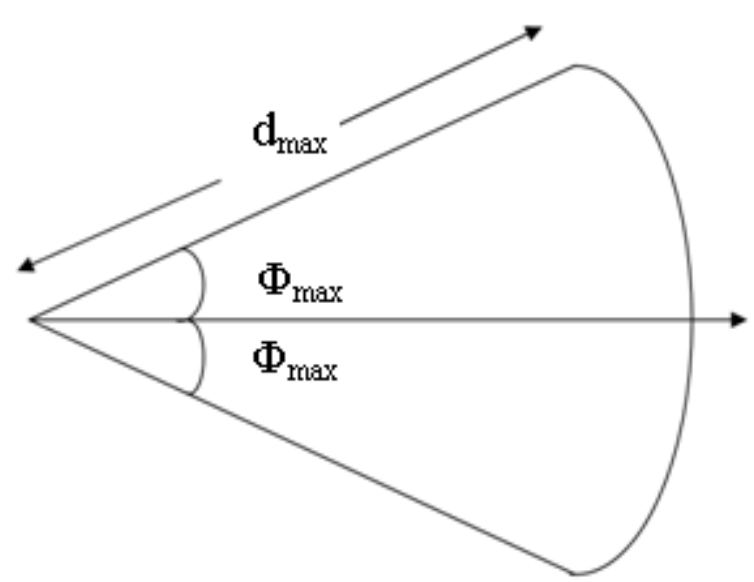

Figure.2 Producer scanning field 


\subsubsection{Initialize the Search Solution as well as the Head Angle}

The solution that is obtained after searching takes the thickness, period, the wall size and the temperature applied into account.

$$
Z_{i}=\left[\begin{array}{ll}
z_{11} & z_{12} \ldots \ldots \\
z_{21} & z_{22} \ldots \ldots z_{1 m} \\
z_{n 1} & z_{n 2} \ldots \ldots . . z_{n m}
\end{array}\right]
$$

For every individual, the head angle can be stated as in equation (2).

$$
\Psi_{i}^{s}=\left(\Psi_{i 1}^{s} \ldots \ldots \ldots . . \Psi_{i(n-1)}^{s}\right)
$$

The member's direction of search relies on the head angle and it is given as in equation (3).

$$
L_{i}^{S}\left(\Psi_{i}^{S}\right)=\left(l_{i 1}^{s} \ldots \ldots \ldots . . . l_{i(n)}^{S}\right)
$$

In equation (2) and (3) $\psi$ is the head angle $L(\psi)$ is the direction of head angle.

Polar and Cartesian coordinate transformation is employed to assess the direction of search in accordance with the head angle.

$$
\begin{aligned}
L_{i 1}^{S} & =\prod_{p=1}^{n-1} \cos \left(\Psi_{i p}^{S}\right) \\
L_{i j}^{S} & =\sin \left(\Psi_{i(j-1)}^{S} \prod_{p=j}^{n-1} \cos \left(\Psi_{i p}^{S}\right)\right.
\end{aligned}
$$

where, $j=2 \ldots n-1$

$$
L_{i n}^{S}=\sin \left(\Psi_{i(n-1)}^{S}\right)
$$

\subsubsection{Fitness Function}

Optimization in the mathematical modeling can be accomplished using the sigmoid function, when it is included in the process involving artificial neural network. The optimized mathematical model can be yielded with the optimization of $\alpha_{i j}$ and $\beta_{i j}$ in the function.

$$
f_{i}=\sum_{j=1}^{h} \alpha_{j} *\left[\frac{1}{1+\exp \left(-\sum_{i=1}^{N} Z_{i} \beta_{i j}\right)}\right]
$$

Above equation (7) $\alpha_{i}$ and $\beta_{i j}$ are weights in mathematical modeling, $h$ is the number of neurons, $Z_{i}$ is the input parameters and $N$ is the number of data.

\subsubsection{Find the Producer $Z_{p}$ of the Group}

The member with the best fitness of $Z_{i}$ is called as the producer and it is specified as $Z_{p}$.

\section{- Producer Performance}

During the execution of the GSO algorithm, the activity of the producer $Z_{p}$ at ' $s$ ' iteration can be elucidated as follows:

(i) The producer performs the scanning operation at zero degree

$$
Z_{z}=Z_{p}^{s}+\varepsilon_{1} d_{\max } L_{p}^{s}\left(\Psi^{s}\right)
$$

(ii) The producer performs the scanning operation at the right hand side hypercube

$$
Z_{r}=Z_{p}^{s}+\varepsilon_{1} d_{\max } L_{p}^{s}\left(\Psi^{s}+\varepsilon_{2} \Phi_{\max } / 2\right)
$$

(iii) The producer performs the scanning operation at the left hand side hypercube

$$
Z_{l}=Z_{p}^{s}+\varepsilon_{1} d_{\max } L_{p}^{s}\left(\Psi^{s}-\varepsilon_{2} \Phi_{\max } / 2\right)
$$

Where, $\varepsilon_{l}$ points to a normally distributed random number with zero mean and unity standard deviation, $\varepsilon_{2}$ stands for a uniformly distributed random sequence that takes value between zero and one.

The maximum search angle $\Phi_{\max }$ can be expressed as:

$$
\Phi_{\max }=\frac{\pi}{c^{2}}
$$

Here, the constant $c$ can be stated as:

$$
C=\operatorname{round}(\sqrt{n+1})
$$

Where, $\mathrm{n}$ denotes the dimension of the search space.

$$
\therefore \Phi_{\max }=\frac{\pi}{n+1}
$$

The computation of maximum search distance $d_{\max }$ involves the following equations.

$$
\begin{aligned}
d_{\max } & =\left\|d_{U}-d_{L}\right\| \\
d_{\max } & =\sqrt{\sum_{i=1}^{n}\left(d_{U i}-d_{L i}\right)^{2}}
\end{aligned}
$$

Where, $d_{U i}$ and $d_{L i}$ indicates the upper limit and the lower limit of $i$ th dimension, respectively.

The best location containing the most useful resource can be obtained with the help of equation (9), equation (10) and equation (11). The present best location would take a new best location, if its resource is found as not better than that in the new location. Else, the producer will maintain its location and turn its head according to the head angle direction that is arbitrarily generated using equation (16).

$$
\Psi^{s+1}=\Psi^{s}+\varepsilon_{2} \tau_{\max }
$$

Where, $\tau_{\max }$ indicates the maximum turning 
angle that is computed using the following equation.

$$
\tau_{\max }=\frac{\Phi_{\max }}{2}
$$

When the producer is unable to identify a better position even after the completion of $m$ iterations, its head would then assume its initial position as given in equation (18).

$$
\Psi^{s+c}=\Psi^{s}
$$

\section{- Scrounger performance}

In all iterations, several members that exclude the producer are also chosen and they are called as scroungers. The scrounging action of GSO usually involves the area copying activity. During the sth iteration, the activity of area copying that the $i$ th scrounger performs can be modeled as a motion to reach the producer in a closer way and it is expressed as:

$$
Z^{s+1}=Z_{i}^{s}+\varepsilon_{3} o\left(Z_{p}^{s}-Z_{i}^{s}\right)
$$

Where, o specifies the Hadamard product that computes the product of the two vectors in an entrywise manner and $\varepsilon_{3}$ denotes a uniform random sequence lying in the interval of $(0,1)$. The $i$ th scrounger continues its searching activity to make a choice of the better occasion for linking. The designing of the scrounging action involves the turning of the head in the ith scrounger to a novel and arbitrarily generated angle as depicted in equation (16).

\section{- Ranger performance}

The rangers are the remaining members of the group, which have been displaced from their present location. The head angle as well as the distance associated with the ranger is generated in a random fashion.

$$
d_{i}=c \cdot \varepsilon_{1} \cdot d_{\max }
$$

The random walk to a novel point can be expressed as:

$$
Z^{s+1}=Z_{i}^{s}+d_{i} L_{i}^{s}\left(\Psi^{s+1}\right)
$$

Once the entire process gets completed, the fitness of the updated solution is evaluated. The best solution will be gained, if the process is repeated for's' number of iterations. The GSO and the related mathematical modeling allow the temperature of the wall to be envisaged effectively.

\section{Result and discussion}

In this study, the parameters such as thickness of wall, applied temperature, area and time for ferro cement wall, RCC wall, cavity wall 1, cavity wall 2 and cavity wall 3 . For finding the temperature three algorithms were utilized such as CS, BCO and GSO algorithm. Group search optimization algorithm is used with mathematical modeling to reduce the time interval. The temperature variation of the reverse face is attained in the real time experiments.

In this fig.3, shows that the variations of error graph for ferrocement wall on reverse face. The group search optimization algorithm is performed using mathematical modeling and it reduces the error level. The level of error varies 0 to 12 and the data varies 1 to 11 . When comparing with other two algorithms CS and BCO the GSO algorithm is performed better while reduce the error value.

Fig. 4 shows that the variation of error for RCC wall on reverse face and it was measured by $\mathrm{CS}$, $\mathrm{BCO}$ and GSO algorithms.

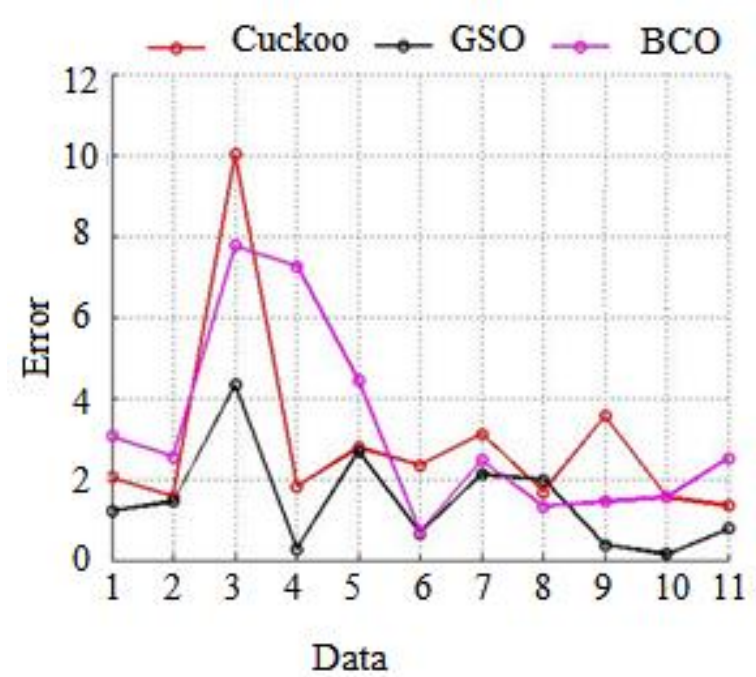

Figure.3 Variation of error graph for ferrocement wall

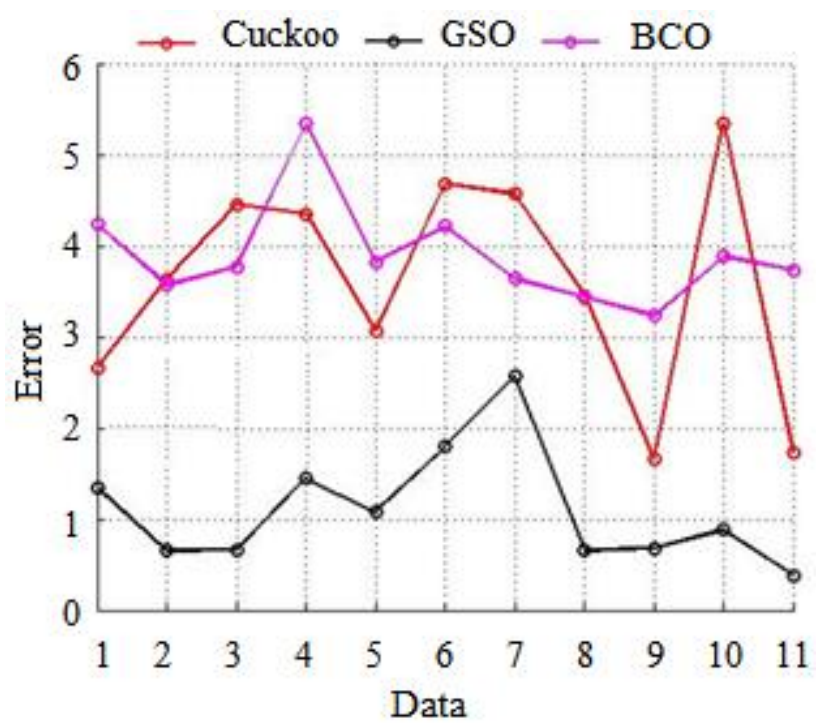

Figure.4 Variation of error graph for RCC wall 
The GSO algorithm is used to reduce the error, in this RCC wall the error varies 0 to 6 and the data varies 1 to 11 , generally the GSO starts with reduction of error 1.4 and data is 1 up to 11 the value is extended. When comparing with other two algorithms the GSO algorithm is performed better while reduce the error value.

Table 1. Comparison of output for ferrocement wall

\begin{tabular}{|c|c|c|c|c|c|c|c|c|}
\hline \multicolumn{2}{|c|}{ Input } & \multicolumn{4}{c|}{ Output } \\
\hline Sl.no & Area & Thickness & Testing & Time & Measured & \multicolumn{2}{|c|}{ Obtained value } \\
\cline { 7 - 9 } & & & temperature & & value & CS & GSO & BCO \\
\hline 1. & 1 & 25 & 40 & 40 & 26.5 & 28.54 & 25.28 & 29.56 \\
\hline 2. & 1 & 25 & 40 & 50 & 27 & 25.43 & 28.45 & 24.45 \\
\hline 3. & 1 & 25 & 40 & 90 & 30.2 & 40.21 & 34.52 & 22.43 \\
\hline 4. & 1 & 25 & 40 & 130 & 31.5 & 33.32 & 31.75 & 24.24 \\
\hline 5. & 1 & 25 & 40 & 160 & 33 & 30.22 & 35.69 & 37.45 \\
\hline 6. & 1 & 25 & 50 & 0 & 18 & 15.66 & 18.66 & 17.33 \\
\hline 7. & 1 & 25 & 50 & 30 & 26 & 22.89 & 28.11 & 23.54 \\
\hline 8. & 1 & 25 & 50 & 60 & 32 & 30.33 & 33.99 & 30.66 \\
\hline 9. & 1 & 25 & 50 & 80 & 35 & 38.55 & 35.36 & 33.54 \\
\hline 10. & 1 & 25 & 50 & 100 & 36 & 34.44 & 35.84 & 37.55 \\
\hline 11. & 1 & 25 & 50 & 130 & 37 & 35.66 & 36.22 & 39.51 \\
\hline
\end{tabular}

Table 2. Comparison of output for RCC wall

\begin{tabular}{|c|c|c|c|c|c|c|c|c|}
\hline \multicolumn{5}{|c|}{ Input } & \multicolumn{4}{|c|}{ Output } \\
\hline \multirow[t]{2}{*}{ Sl.no } & \multirow[t]{2}{*}{ Area } & \multirow[t]{2}{*}{ Thickness } & \multirow{2}{*}{$\begin{array}{c}\text { Testing } \\
\text { temperature }\end{array}$} & \multirow[t]{2}{*}{ Time } & \multirow{2}{*}{$\begin{array}{l}\text { Measured } \\
\text { value }\end{array}$} & \multicolumn{3}{|c|}{ Obtained value } \\
\hline & & & & & & CS & GSO & BCO \\
\hline 1. & 1 & 40 & 40 & 40 & 23 & 20.34 & 24.34 & 27.23 \\
\hline 2. & 1 & 40 & 40 & 80 & 25.8 & 29.43 & 26.45 & 22.23 \\
\hline 3. & 1 & 40 & 40 & 130 & 29 & 33.45 & 28.33 & 25.23 \\
\hline 4. & 1 & 40 & 40 & 160 & 30 & 34.34 & 28.56 & 35.34 \\
\hline 5. & 1 & 40 & 50 & 10 & 20.5 & 17.43 & 19.42 & 24.32 \\
\hline 6. & 1 & 40 & 50 & 50 & 25.02 & 20.34 & 23.23 & 29.23 \\
\hline 7. & 1 & 40 & 50 & 90 & 29.8 & 25.23 & 27.23 & 33.43 \\
\hline 8. & 1 & 40 & 60 & 0 & 18.8 & 15.35 & 19.45 & 22.23 \\
\hline 9. & 1 & 40 & 60 & 60 & 35 & 33.34 & 34.32 & 38.23 \\
\hline 10. & 1 & 40 & 60 & 120 & 42 & 47.34 & 41.12 & 38.12 \\
\hline 11. & 1 & 40 & 60 & 130 & 42.5 & 44.23 & 42.12 & 46.23 \\
\hline
\end{tabular}

Table 3. Comparison of output for combined ferrocement and RCC wall

\begin{tabular}{|c|c|c|c|c|c|c|c|c|}
\hline & \multicolumn{4}{|c|}{ Input } & \multicolumn{4}{|c|}{ Output } \\
\hline \multirow[t]{2}{*}{ Sl.no } & \multirow[t]{2}{*}{ Area } & \multirow[t]{2}{*}{ Thickness } & \multirow{2}{*}{$\begin{array}{c}\text { Testing } \\
\text { temperature }\end{array}$} & \multirow[t]{2}{*}{ Time } & \multirow{2}{*}{$\begin{array}{l}\text { Measured } \\
\text { value }\end{array}$} & \multicolumn{3}{|c|}{ Obtained value } \\
\hline & & & & & & CS & GSO & BCO \\
\hline 1. & 1 & 90 & 40 & 0 & 18.5 & 20.54 & 18.50 & 15.64 \\
\hline 2. & 1 & 90 & 40 & 40 & 20 & 17.56 & 21.47 & 24.13 \\
\hline 3. & 1 & 90 & 40 & 90 & 22 & 24.64 & 22.95 & 20.54 \\
\hline 4. & 1 & 90 & 40 & 140 & 23.5 & 20.55 & 23.49 & 25.56 \\
\hline 5. & 1 & 90 & 40 & 170 & 24.8 & 21.51 & 23.49 & 26.51 \\
\hline 6. & 1 & 90 & 50 & 10 & 20 & 17.51 & 19.08 & 21.55 \\
\hline 7. & 1 & 90 & 50 & 50 & 22 & 24.51 & 21.40 & 19.41 \\
\hline 8. & 1 & 90 & 50 & 110 & 25.1 & 20.16 & 23.41 & 28.1 \\
\hline 9. & 1 & 90 & 60 & 0 & 18.5 & 16.13 & 19.08 & 21.2 \\
\hline 10. & 1 & 90 & 60 & 40 & 22.8 & 25.35 & 21.40 & 19.55 \\
\hline 11. & 1 & 90 & 60 & 160 & 31 & 24.36 & 22.17 & 19.45 \\
\hline
\end{tabular}


Table.4 Comparison of output for combined two ferrocement walls

\begin{tabular}{|c|c|c|c|c|c|c|c|c|}
\hline \multicolumn{5}{|c|}{ Input } & \multicolumn{4}{|c|}{ Output } \\
\hline \multirow[t]{2}{*}{ Sl.no } & \multirow[t]{2}{*}{ Area } & \multirow[t]{2}{*}{ Thickness } & \multirow{2}{*}{$\begin{array}{c}\text { Testing } \\
\text { temperature }\end{array}$} & \multirow[t]{2}{*}{ Time } & \multirow{2}{*}{$\begin{array}{l}\text { Measured } \\
\text { value }\end{array}$} & \multicolumn{3}{|c|}{ Obtained value } \\
\hline & & & & & & $\mathrm{CS}$ & GSO & BCO \\
\hline 1. & 1 & 120 & 40 & 90 & 27.6 & 30.55 & 27.03 & 25.36 \\
\hline 2. & 1 & 120 & 40 & 100 & 28 & 26.25 & 28.30 & 31.63 \\
\hline 3. & 1 & 120 & 40 & 140 & 30 & 33.52 & 29.91 & 27.36 \\
\hline 4. & 1 & 120 & 40 & 170 & 30.8 & 27.36 & 31.76 & 34.63 \\
\hline 5. & 1 & 120 & 50 & 0 & 25 & 29.55 & 28.34 & 31.63 \\
\hline 6. & 1 & 120 & 50 & 10 & 25.2 & 35.26 & 32.53 & 30.36 \\
\hline 7. & 1 & 120 & 50 & 50 & 28 & 21.36 & 29.78 & 30.85 \\
\hline 8. & 1 & 120 & 50 & 110 & 32.2 & 26.35 & 31.82 & 25.36 \\
\hline 9. & 1 & 120 & 50 & 150 & 34 & 31.25 & 35.38 & 37.25 \\
\hline 10. & 1 & 120 & 50 & 170 & 34.7 & 30.96 & 33.73 & 30.25 \\
\hline 11. & 1 & 120 & 60 & 40 & 29.2 & 23.55 & 25.44 & 22.36 \\
\hline
\end{tabular}

Table.5 Comparison of output for combined two RCC wall

\begin{tabular}{|c|c|c|c|c|c|c|c|c|}
\hline \multicolumn{5}{|c|}{ Input } & \multicolumn{4}{|c|}{ Output } \\
\hline \multirow[t]{2}{*}{ S1.no } & \multirow[t]{2}{*}{ Area } & \multirow[t]{2}{*}{ Thickness } & \multirow{2}{*}{$\begin{array}{c}\text { Testing } \\
\text { temperature }\end{array}$} & \multirow[t]{2}{*}{ Time } & \multirow{2}{*}{$\begin{array}{l}\text { Measured } \\
\text { value }\end{array}$} & \multicolumn{3}{|c|}{ Obtained value } \\
\hline & & & & & & CS & GSO & BCO \\
\hline 1. & 1 & 105 & 40 & 0 & 26 & 28.56 & 26.57 & 29.63 \\
\hline 2. & 1 & 105 & 40 & 40 & 27.5 & 30.32 & 27.46 & 29.2 \\
\hline 3. & 1 & 105 & 40 & 130 & 30.4 & 28.36 & 30.02 & 32.52 \\
\hline 4. & 1 & 105 & 50 & 20 & 26.5 & 22.36 & 27.47 & 24.63 \\
\hline 5. & 1 & 105 & 50 & 90 & 30.6 & 32.63 & 29.35 & 29.22 \\
\hline 6. & 1 & 105 & 50 & 180 & 33.5 & 36.33 & 30.02 & 29.22 \\
\hline 7. & 1 & 105 & 60 & 20 & 26.5 & 23.66 & 27.48 & 29.36 \\
\hline 8. & 1 & 105 & 50 & 60 & 29 & 33.69 & 28.33 & 26.36 \\
\hline 9. & 1 & 105 & 50 & 90 & 30.5 & 27.63 & 29.81 & 32.63 \\
\hline 10. & 1 & 105 & 50 & 130 & 33.2 & 36.96 & 30.02 & 30.36 \\
\hline 11. & 1 & 105 & 60 & 170 & 35.5 & 37.96 & 34.02 & 31.69 \\
\hline
\end{tabular}

In this table.1, shows that the inputs were utilized to optimize the temperature for ferrocement wall such as area, thickness, testing temperature and time. The comparison of three algorithms GSO performs better for ferrocement wall.

Table. 2 shows that the inputs were utilized to optimize the temperature for RCC wall such as area, thickness, testing temperature and time. The comparison of three algorithms GSO performs better for RCC wall.

Table. 3 shows that the inputs were utilized to optimize the temperature for combined ferrocement and RCC wall such as area, thickness, testing temperature and time. The comparison of three algorithms GSO performs better for combined walls. the RCC wall error value this graph also the proposed method compared to BCO the difference is $85.63 \%$ and the cavity wall performance of temperature the original value compared to the optimization techniques the minimum error attained in the GSO process the error nearby value is 99.75\%.Then the next figure shows the cavity wall 2 that is combined two ferrocement wall panel temperature values.

Table. 4 has shown that the inputs were utilized to optimize the temperature for combined two ferrocement walls such as area, thickness, testing temperature and time. The comparison of three algorithms the GSO performs better for combined two ferrocement walls.

Table.5 shows that the inputs were utilized to optimize the temperature for combined two RCC walls such as area, thickness, testing temperature and time. Based on three algorithms the better performance was presented by GSO algorithms. Above mention tables shown that the testing results 
of the mathematical modeling process for the different wall of thermal insulation material. Ferrocement, RCC wall and different cavity wall temperature to be obtained based on the area, thickness, time and testing temperature values. The entire wall the temperature value nearby value attained in GSO process. Arithmetical model with proposed optimization compared to the other techniques the difference is $56.38 \%$ temperature also the nearby value attained in the GSO.

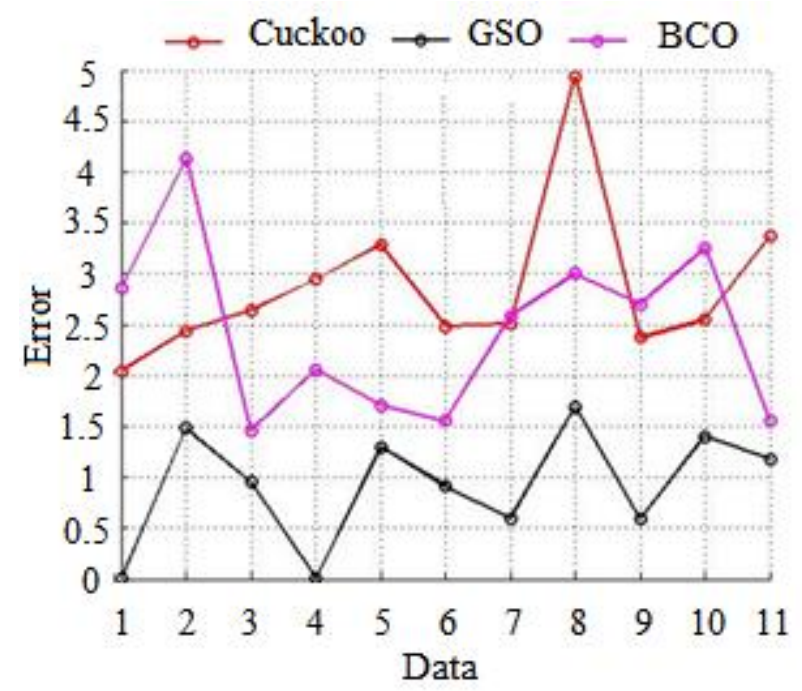

Figure.5 Variation of error graph for combined ferrocement and RCC Wall

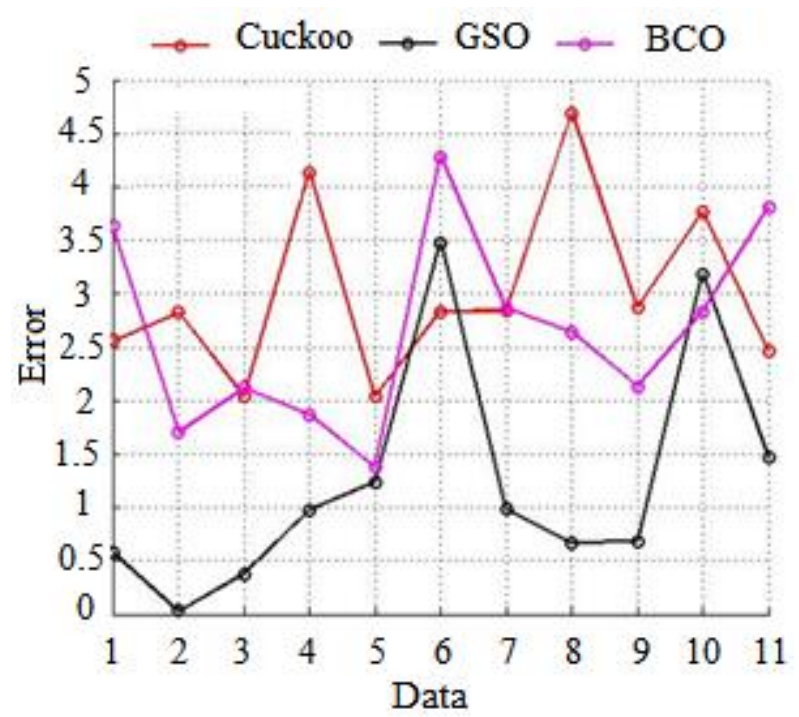

Figure.6 Variation of error graph for combined two ferrocement Walls

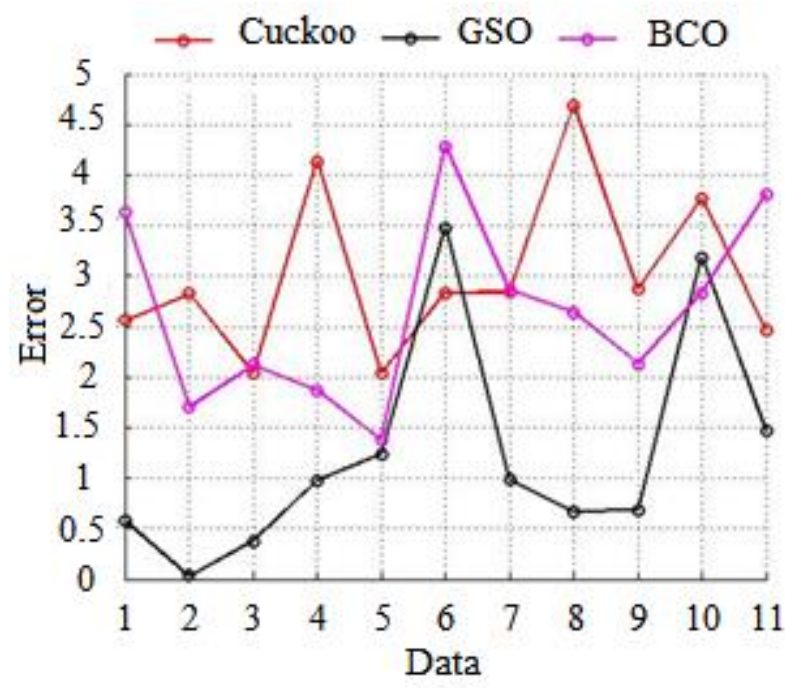

Figure.7 Variation of error graph for combined two RCC Walls

In fig.5 shows the variation of error for combined ferrocement and RCC wall on reverse face. The variations of error for combined ferrocement wall were measured by three algorithms named as CS, BCO and GSO. The GSO algorithm is used to reduce the error value, in this cavity wall 1 the error is varies 0 to 5 and the data varies 1 to 11 . When comparing with other two algorithms the GSO algorithm is performed better while reduce the error value.

The variation of temperature for combined two ferrocement wall on reverse face is shown in fig.6. The variation of error graph for combined two ferrocement wall were measured by three algorithms named as CS, BCO and GSO. In this, GSO has been reducing the error level, it starts from the stage of 0 to 5 and the data is 1 to 11 in this variation of combined two ferrocement wall. When comparing with other two algorithms the GSO algorithm is performed better while reduce the error value.

In fig.7 the variation of error for combined two RCC walls on reverse face is shown. The variation of error graph for combined two RCC wall were measured by three algorithms named as CS, BCO and GSO. GSO algorithm reduces the walls error, it starts from 0 to 6 and the data is varies from 1 to 11 for this combined two RCC walls. When comparing with other two algorithms the GSO algorithm is performed better while reduce the error value.

\section{Convergence graph}




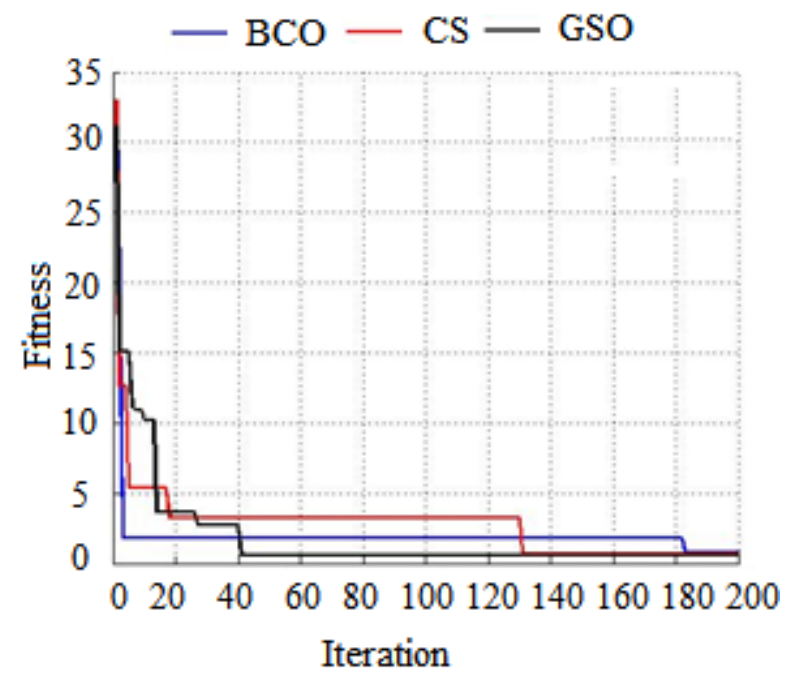

Figure.8 Convergence graph

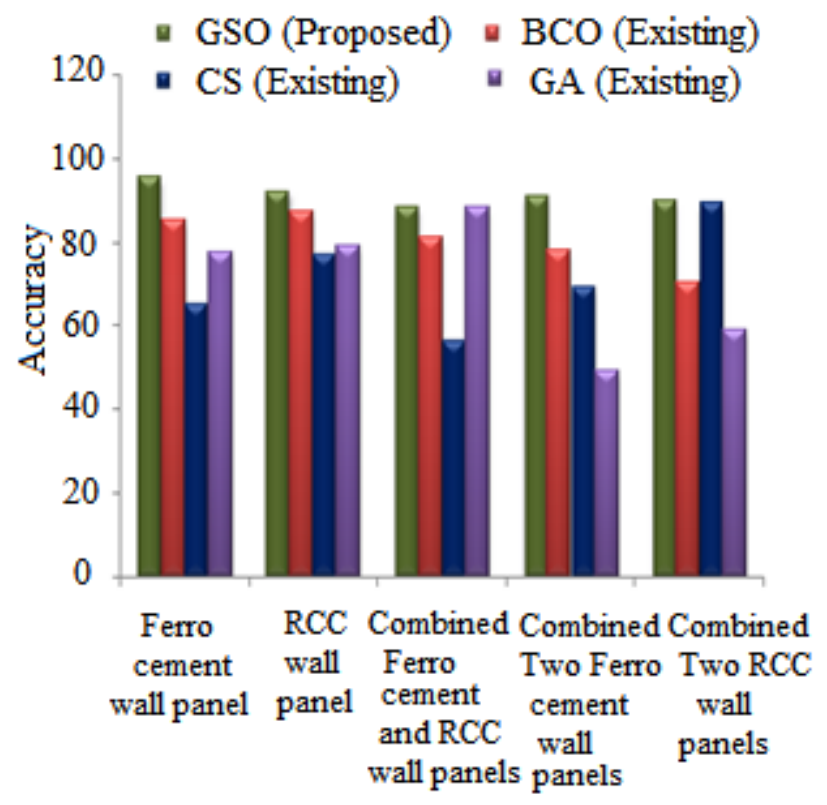

Figure.9 Comparative analysis

Fig. 8 shows the Convergence graph it is plotted between the iteration and fitness estimations of the various strategies for example BCO, CS and GSO. Based on the three algorithms the GSO is performed better in convergence graph.

Figure 9 Show the different wall error temperature value for proposed method and existing process . Existing process CS, BCO, CS and Genetic Algorithm (GA) are existing techniques, its compared to proposed GSO model the total accuracy difference is $56.23 \%$. Ferrocement wall the minimum error value is $98.23 \%$ in GSO similar values are attained in the all the wall. The total difference of the proposed method and existing method is $96.5 \%$ of the all wall panels. The main advantage of this research work improves the prediction level different walls the temperature analyzed.

\section{Conclusion}

In this paper, the thermal insulation materials are used to reduce the heat of various walls. In the construction the mathematical modeling is used and the designing of the objective function is centered on the evaluation of the output parameter. Certain optimization techniques like the cuckoo search (CS), the bacterial colony optimization (BCO) and the group search optimization (GSO) are effectively employed to ascertain the optimal weight of the system. From the evaluation the GSO algorithm is found to reduce the temperature level and the graph shows the error minimization when compared with the other two algorithms. In the overall process the average is $96.8 \%$ and the GSO algorithm shows the enhanced performance. Further researchers can perform this prediction process considering Feed Forward back propagation Neural Netork (FFBN) with new own optimization techniques to improve the accuracy level of prediction process.

\section{Reference}

[1] V. Patel and N. Shah, "A Survey of High Performance Concrete Developments in Civil Engineering Field", Journal of Civil Engineering, Vol. 3, No. 2, pp. 69-79, 2013.

[2] K. W. Hoe and M. Ramli, "Rational Mix Design Approach for High Strength Concrete Using Sand with very High Fineness Modulus", Journal of Applied Sciences, Vol. 7, No. 12, pp. 1562-1568, 2010.

[3] M. M. A. Bakri, Mohammed, Kamarudin, K. Niza and Zarina, "Review on fly ash-based geopolymer concrete without Portland Cement ", Journal of Engineering and Technology Research, Vol. 3, No. 1, pp. 1-4, 2011.

[4] M. C. Onyeaju, E. Osarolube, E. O. Chukwuocha, C. E. Ekuma and G. A. J. Omasheye, "Comparison of the Thermal Properties of Asbestos and Polyvinylchloride (PVC) Ceiling Sheets", Journal of Materials Sciences and Applications, Vol. 3, pp. 240-244, 2012.

[5] A. Bashandy, "Experiments On Flexural Strengthening Of Reinforced Concrete Beams Using Valid Strengthening Techniques", Journal of Civil Engineering \& Architecture Vol. 56, No. 1, pp. 1-15, 2013.

[6] S. Mohammad and A. Shea, "Performance Evaluation of Modern Building Thermal Envelope Designs in the Semi-Arid Continental Climate of 
Tehran", Journal of Buildings, Vol. 3, No. 4, pp. 674-688, 2013.

[7] B. M. Suman and R. K. Srivastava, "Effect of air gap on thermal performance of composite wall section", Journal of Science and Technology, Vol. 1, No. 5, pp. 1-4, 2008.

[8] R. K. Makode, S. Akhtar and G. Batham, "Dynamic Analysis of Multistory RCC Building Frame with Flat Slab and Grid Slab", Journal of Engineering Research and Applications, Vol. 4, No. 2, pp. 416420, 2014.

[9] B. V. Bahoria and D. Parbat, "Analysis and Design of RCC and Post-tensioned Flat Slabs Considering Seismic Effect", Journal of Engineering and Technology, Vol. 5, No. 1, pp. 10-14, 2013.

[10] Bauchkar and Chore, "Roller Compacted Concrete: A Litrature Review", Journal of Mechanical and Civil Engineering, pp. 28-32.

[11] Sakthivel, Ravichandran and Alagumurthi, "Innovative Applications of Steel-Mesh Reinforced Cementitious Composites", Journal of Emerging Technology and Advanced Engineering, Vol. 4, No. 9, pp. 429-434, 2014.

[12] S. Dharane and A. Male, "Experimental Performance of Flexural Creep Behavior of Ferro cement Slab, Journal of Research in Engineering and Technology, pp. 635-640, 2014.

[13] B. Kumar and A. K. Ahuja, "Comparison of Thermal Insulation Properties of Various Construction Materials", Journal of Academia and Industrial Research, Vol. 2, No. 12, pp. 693-696, 2014.

[14] B. M. Suman and R. K. Srivastava, "Influence of Thermal Insulation on Conductive Heat Transfer through Roof Ceiling Construction", Journal of Indian Building Congress, Vol. 68, pp. 248-251, 2009.

[15] N. Kulkarni and Gaidhankar, "Analysis and Design of Ferrocement Panels an Experimental Study", Journal of Inventive Engineering and Sciences, Vol. 1, No. 5, pp. 1-8, 2013.
[16] N. J. George, V.I Obianwu , G.T. Akpabio and I.B Obot, "Comparison of thermal insulation efficiency of some select materials used as ceiling in building desig", Journal of Archives of Applied Science Research, Vol. 2, No. 2, pp. 253-259, 2010.

[17] Thayapraba M., "Cost Effectiveness of Post Tensioned and Reinforced Concrete Flat Slab Systems", Journal of Innovative Technology and Exploring Engineering, Vol. 3, No. 12, pp. 107-109, 2014.

[18] M. V. Shoubi, M. V. Shoubi, A. Bagchi and A. S. Baroug, "Reducing the operational energy dema nd in buildings using building informa tion modeling tools and sustainability approaches", Journal of Ain Shams Engineering, Vol. 6, pp. 41-55, 2015.

[19] P. Biddulph, V. Gori, C. Elwell , C. Scott, C. Rye, R. Lowe and T. Oreszczyn, "Inferring the thermal resistance and effective thermal mass of a wall using frequent temperature and heat flux measurements" , Energy and Buildings, Vol. 78, pp. 10-16, 2014.

[20] C. Sangluaia, M. K. Haridharan, C. Natarajan and A. Rajaraman, "Behaviour of Reinforced Concrete Slab Subjected To Fire", Journal of Computational Engineering Research, Vol. 3, No. 1, pp. 195-206, 2013.

[21] V. Rahman and Mundhada, "Comparative Study of RCC and Prestressed Concrete Flat Slabs", Journal of Modern Engineering Research, Vol. 3, No. 3, pp. 1727-1730, 2013.

[22] Thirumal J. R., "The Behavior of Fiber Reinforced Ferro-cement Slabs Under Impact Is Studied With Mesh Named G.I. Steel Weld Mesh And A Synthetic Fiber Named Polyolefin", Journal of Biotech Trends and Technology, Vol. 2, No. 5, pp. 31-53, 2012.

[23] G. Babu and A. Yerramala, "Strength Properties of High Workable And High Volume Fly Ash Roller Compacted Concrete", Journal of Engineering Research and Studies, pp. 1-7, 2012. 